\title{
Valvular heart disease
}

\author{
The national society journals present selected research that has driven recent advances \\ in clinical cardiology
}

\section{Raphael Rosenhek}

The article was first published in Heart (Heart 2011;97(24):2007-2017, doi:10.1136/heartjnl-2011-301396) and in republished with permission.

\section{Introduction}

$\mathbf{W}$

ith an ageing population and improved diagnostic modalities, the number of patients with valvular heart disease is dramatically increasing. Considering projected changes in the age distribution, a further accentuation of this trend can be expected and this may indeed be considered "the next cardiac epidemic". 1 Obviously, we are faced with more complex decisions in patients with advanced age and increasing comorbidities. Advances in percutaneous valve interventional techniques have entered into routine practice. At the same time, new data on the natural history of disease and the identification of predictors of outcome permit improvement in the decision-making process and management of patients with valvular heart disease.

\section{Aortic stenosis}

\section{Disease progression}

In a population-based study which followed up 953 subjects for 10 years, a high prevalence of calcific aortic valve disease (28\%) associated with long-term exposure to raised cholesterol levels and active smoking was described. ${ }^{2}$ Intraleaflet haemorrhage (detected by immunohistochemistry at the moment of aortic valve replacement surgery) was frequently present in the valve leaflets of degenerative aortic stenosis (AS) and was associated with rapid progression of AS. ${ }^{3}$ In a small study of 164 patients with rheumatic AS (of whom 30 were treated with a statin), progression of AS was slower in patients receiving statins than in untreated patients (annual change of peak aortic velocity: $0.05 \pm 0.07 \mathrm{~m} / \mathrm{s} /$ year vs $0.12 \pm 0.11 \mathrm{~m} / \mathrm{s} /$ year, $p=0.001){ }^{4}$ On the other hand, in the ASTRONOMER trial, a randomised double-blind study, that allocated 269 patients to rosuvastatin $40 \mathrm{mg}$ daily or to placebo, statin treatment did not reduce progression of the disease in patients with AS. ${ }^{5}$

\section{Predictors of outcome}

Based on the aortic jet velocity and the B-type natriuretic peptide (BNP) level, a risk score predicting outcome in patients with moderate-to-severe asymptom- atic AS was derived and validated in an independent cohort: score $=($ peak velocity $(\mathrm{m} / \mathrm{s}) \times 2)+($ In of BNP $\times$ $1.5)+1.5$ (if female sex). Event-free survival after 20 months was particularly poor (7\%) for patients in the fourth quartile. ${ }^{6}$ In a separate study of patients with severe asymptomatic AS, event-free survival rates at 3 years were $49 \%, 33 \%$ and $11 \%$ for patients with peak aortic jet velocities between 4.0 and $5.0 \mathrm{~m} / \mathrm{s}, 5.0$ and $5.5 \mathrm{~m} / \mathrm{s}$ or $>5.5 \mathrm{~m} / \mathrm{s}$, respectively. In addition to the important implications for risk stratification, these data introduce us to the entity of "very severe aortic stenosis" based on a peak aortic jet velocity $\geq 5.0 \mathrm{~m} / \mathrm{s} .{ }^{7}$ In another study, receiver-operator curve analysis identified a peak aortic jet velocity $\geq 4.4 \mathrm{~m} / \mathrm{s}$, a left ventricular (LV) longitudinal myocardial deformation $\leq 5.9 \%$, a valvular-arterial impedance $\geq 4.9 \mathrm{~mm} \mathrm{Hg} / \mathrm{ml} / \mathrm{m}^{2}$ and an indexed left atrial area $\geq 12.2 \mathrm{~cm}^{2} / \mathrm{m}^{2}$ as factors associated with adverse outcomes in 163 patients with moderate to severe AS. ${ }^{8}$ Early elective surgery was performed on 102 patients with severe AS (valve area $\leq 0.75 \mathrm{~cm}^{2}$, AV-velocity $\geq 4.5 \mathrm{~m} / \mathrm{s}$ ), and conventional treatment was used for 95 patients. Compared with conventional treatment, early surgery in patients with very severe AS was associated with improved long-term survival by decreasing cardiac mortality. ${ }^{9}$ However, this was not a randomised study and selection bias might have affected the results.

In asymptomatic patients with AS ( $n=135)$ and a normal exercise response, an exercise-induced increase in mean transvalvular gradient $>20 \mathrm{~mm} \quad \mathrm{Hg}$ was described as an independent risk predictor. These results thus suggest that exercise stress echocardiography may provide prognostic information additional to that obtained by standard exercise testing and resting echocardiography. ${ }^{10}$ Symptoms on treadmill exercise testing in 38 apparently asymptomatic patients with at least moderate AS were associated with a lower peak myocardial $\mathrm{VO}_{2}$, a lower peak stroke index during exercise and BNP levels. ${ }^{11}$ Increased valvuloarterial impedance (Z(va)) (which is calculated by dividing the estimated LV systolic pressure (systolic arterial pressure + mean transvalvular gradient) by the stroke volume indexed for the body surface area) is a marker of excessive LV haemodynamic load, and a value $>3.5$ successfully identifies patients with AS with a poor outcome. ${ }^{12}$ However, the clinical value of this measure remains to be fully determined. 
The prognostic significance of mid-wall fibrosis and infarct patterns detected by late gadolinium enhancement was evaluated in 143 patients with aortic stenosis. Mid-wall fibrosis ( $H R=5.35 ; p=0.03$ ) and ejection fraction ( $\mathrm{HR}=0.96 ; p=0.01$ ) were independent predictors of all-cause mortality and may provide a useful method of risk stratification. ${ }^{13}$ There is evidence of subclinical myocardial dysfunction early in the disease process despite normal left ventricular ejection fraction (LVEF). The myocardial dysfunction appears to start in the subendocardium and to progress to transmural dysfunction with increasing AS severity. Symptomatic patients with AS have more impaired multidirectional myocardial functions than asymptomatic patients. ${ }^{14}$ In patients with severe AS, impaired multidirectional LV strain and strain rate are present even with preserved LVEF, but a significant improvement occurs after aortic valve replacement (AVR). ${ }^{15}$ Lower average longitudinal strain is related to higher LV mass, concentric geometry and more severe AS. ${ }^{16}$ Inappropriately high LV mass was found in $58 \%$ of asymptomatic patients with severe AS and was related to cardiovascular events. Event-free survival for patients with appropriate and inappropriate LV mass, respectively, was $78 \%$ vs $56 \%$ at 1 year, $68 \%$ vs $29 \%$ at 3 years and $56 \%$ vs $10 \%$ at 5 years (all $p<0.01$ ). ${ }^{17}$ However, in patients with calcific AS and a normal LVEF the severity of stenosis was the most important correlate of symptomatic deterioration. Tissue Doppler measures of LV systolic and diastolic function and LV mass provide limited predictive information after accounting for the severity of stenosis. ${ }^{18}$

\section{Outcome of symptomatic patients with aortic stenosis}

Severe aortic valve stenosis is a medical condition with limited short-term survival for patients over the age of 75 years, particularly those at high surgical risk. Patients with the highest surgical risk have the worst prognosis if AS is not treated. ${ }^{19}$ It has been confirmed, that patients screened but without the inclusion/exclusion criteria necessary to participate in a transcatheter aortic valve implantation trial do poorly and have extremely high mortality rates, especially in non-surgical groups: 274 such patients were treated medically or with balloon aortic valvuloplasty and had a mortality of $37.2 \%$ as compared with a mortality of $21.5 \%$ for 88 patients who underwent AVR (these latter patients were less symptomatic and had a lower EUROscore) during a median follow-up of about 1 year. ${ }^{20}$ In an observational study of 25 patients with severe AS presenting in cardiogenic shock, the use of an intra-aortic balloon pump improved the cardiac index from 1.77 to 2.18 and $2.36 \mathrm{I} /$ $\mathrm{min} / \mathrm{m}^{2}$ at 6 and $24 \mathrm{~h}$, respectively $(\mathrm{p}<0.001)$ and should thus be considered in this critically ill population while being evaluated for further interventions. ${ }^{21}$

\section{Low gradient aortic stenosis}

Five-year survival in patients with low-flow/low-gradient aortic stenosis without contractile reserve was higher in patients undergoing AVR than in medically managed patients ( $54 \pm 7 \%$ vs $13 \pm 7 \%, p=0.001$ ) despite a high operative mortality of $22 \%$. Surgery should thus not be withheld in this subset of patients solely on the basis of lack of contractile reserve on dobutamine stress echocardiography. ${ }^{22}$

Measuring the degree of aortic valve calcification by multislice $\mathrm{CT}$ in patients with mild-to-moderate $\mathrm{AS}$ and an $\mathrm{EF} \geq 40 \%$, showed that a threshold of 1651 arbitrary units provided $82 \%$ sensitivity, $80 \%$ specificity, $88 \%$ negative-predictive value and $70 \%$ positive-predictive value to diagnose severe AS. Performance was best in a subset of patients with low EF when the threshold correctly differentiated between patients with severe AS (the diagnosis was confirmed by mean gradient, natural history or dobutamine stress echocardiography) and those with non-severe AS in 46 of 49 cases. This method may be particularly useful for the evaluation of AS severity in difficult cases, such as patients with reduced EF and low or absent contractile reserve. ${ }^{23}$

On echocardiography approximately one-third of patients with severe aortic valve stenosis, based on aortic valve area $<1.0 \mathrm{~cm}^{2}$, have a non-severe mean pressure gradient ( $\leq 40 \mathrm{~mm} \mathrm{Hg}$ ) despite apparently normal left ventricular function. Three hundred and thirty-three consecutive patients underwent cardiac catheterisation within 30 days after their index echocardiography. On invasive testing, 85 patients (26\%) demonstrated inconsistent grading, with a significantly lower stroke volume and stroke volume index. However, $48 \%$ of inconsistently graded patients had a normal stroke volume index $>35 \mathrm{ml} / \mathrm{m}^{2}$. In the framework of current guidelines inconsistent grading of aortic valve stenosis is common, extends to cardiac catheterisation and is only partially explained by low stroke volume despite apparently normal left ventricular systolic function. ${ }^{24}$ In this SEAS substudy, aortic valve-related events, major cardiovascular events and cardiovascular death in patients with low-gradient "severe" aortic stenosis (aortic valve area $<1.0 \mathrm{~cm}^{2}$ and mean gradient $\leq 40 \mathrm{~mm} \mathrm{Hg}$ ) were comparable to those of patients with moderate stenosis (aortic valve area 1.0 $1.5 \mathrm{~cm}^{2}$; mean gradient $25-40 \mathrm{~mm} \mathrm{Hg}$ ). ${ }^{25}$ These results fuel the debate on the management of such patients. In severe AS, a low gradient is associated with a higher degree of interstitial fibrosis in biopsy samples and more late-enhancement MRI segments, decreased longitudinal function assessed by echocardiography and poorer clinical outcome despite preserved $\mathrm{EF}^{26}$

\section{Experimental studies in aortic stenosis}

Higher serum phosphate levels within the normal range were associated with aortic valve sclerosis and $\mathrm{mi}$ tral and aortic annular calcification in a communitybased cohort of older adults. In contrast, serum calcium, parathyroid hormone and 25-hydroxyvitamin D concentrations were not associated with aortic or mitral calcification. Phosphate may be a new risk factor for calcific aortic valve disease and warrants further study. ${ }^{27}$ The upregulation of the leukotriene pathway in human aortic valve stenosis and its correlation with clinical stenosis 
severity, taken together with the potentially detrimental leucotriene-induced effects on valvular myofibroblasts, suggests one possible role of inflammation in the development of AS. ${ }^{28}$ Mechanical properties of porcine aortic valve leaflets were evaluated: serotonin induced a decrease in the areal stiffness of the cusp, which was reversed by N-nitro-L-arginine-methyl ester or endothelial denudation. Endothelin-1 caused an increase in stiffness, but not in the presence of cytochalasin B. Changes in cusp stiffness were accompanied by aortic cusp relaxations to 5-hydroxytriptamine, which were reversed by endothelial denudation and by N-nitro-L-arginine-methyl ester. These data highlight the role of the endothelium in regulating the mechanical properties of aortic valve cusps and underline the importance of valve cellular integrity for optimal valve function. ${ }^{29}$ A reduced regenerative capacity of valvular endothelial cells due to senescence and decreased levels of endothelial progenitor cells might be, at least in part, a pathological link for the destruction of valvular endothelial cells, resulting in progression of degenerative AS. ${ }^{30}$ Direct in vivo evidence was provided that cathepsin S-induced elastolysis accelerates arterial and aortic valve calcification in chronic renal disease, providing new insight into the pathophysiology of cardiovascular calcification. ${ }^{31}$ In the low-density lipoprotein-receptor-deficient mouse, regular exercise training prevents aortic valve sclerosis by several mechanisms, including the preservation of endothelial integrity, a reduction in inflammation and oxidative stress, and inhibition of the osteogenic pathway. ${ }^{32}$ Recombinant apolipoprotein A-I Milano treatment reverses AS in an experimental rabbit model. The beneficial effects seem to be mediated by enhanced cholesterol removal and by reduced inflammation and calcification. ${ }^{33}$ Additional data indicate that reducing plasma lipid levels by genetic inactivation of the MTTP gene in hypercholesterolaemic mice with early aortic valve disease normalises oxidative stress, reduces pro-osteogenic signalling and halts the progression of aortic valve stenosis. ${ }^{34}$ Patients with AS and diabetes have worse diastolic LV dysfunction, predisposing to heart failure. It appears to result from greater myocardial fibrosis (documented with perioperative LV biopsies), more intra-myocardial vascular advanced glycation end-product deposition and higher cardiomyocyte $F_{\text {passive, }}$ which is related to hypophosphorylation of the N2B titin isoform. ${ }^{35}$

\section{Aortic regurgitation}

In an observational study of 756 patients with severe aortic regurgitation (AR), those taking a $\beta$ blocker $(n=355)$ had significantly better survival rates of $90 \%$ and $70 \%$ at 1 - and 5 -years than patients not receiving treatment ( $75 \%$ and $55 \%$, respectively; $p=0.0009$ ), suggesting that $\beta$-blocker treatment may confer a survival benefit in patients with severe AR. ${ }^{36}$ About one-quarter (191 of 756) of patients with severe AR have at least moderate mitral regurgitation (MR), and in a retrospective cohort study MR was an independent predictor of reduced survival. Moreover, performing AVR plus concomitant mitral valve repair was associated with im- proved survival. These data suggest that the development of MR might provide useful information about the timing of surgery in patients with AR. ${ }^{37}$ Doctors are often reluctant to offer AVR to patients with severe AR and associated severe LV dysfunction ( $E F \leq 35 \%)$, yet a recent study has shown that it results in significantly improved 5 -year survival rates of $70 \%$ as compared with $37 \%$ for patients not receiving surgery. Significantly, however, surgery was only performed in 53 of 166 patients. ${ }^{38}$ In patients with AR macroscopic LV hypertrophy normalises late after AVR, although fibre hypertrophy persists. These changes in LV myocardial structure late after AVR are accompanied by a change in passive elastic properties with persistent diastolic dysfunction. ${ }^{39}$

There is increasing interest in surgical reconstruction procedures and in experienced hands, good early results have been reported. Thus, in 316 patients who underwent reconstruction of regurgitant bicuspid aortic valves hospital mortality was $0.63 \%$ and survival was $92 \%$ at 10 years. Freedom from reoperation at 5 and 10 years was $88 \%$ and $81 \%$, respectively. Predictors of reoperation were age, aortoventricular diameter, effective height, commissural orientation and the use of a pericardial patch. ${ }^{40}$ In another study, an acceptable midterm outcome was reported for aortic valve-sparing surgery. Root repair was performed with either a reimplantation $(74 \%)$ or a remodelling $(26 \%)$ technique. Cusp repair was required more often in bicuspid valves than in tricuspid valves ( $91 \%$ vs $38 \%, p<0.001)$. At 8 years, freedom from reoperation was $90 \pm 7 \%$ and overall survival was $88 \pm 8 \%$. Predictors of recurrent moderate or severe AR were preoperative left ventricular enddiastolic diameter and more than mild AR on discharge echocardiography. ${ }^{41}$

\section{Bicuspid aortic valve disease}

Cardiovascular magnetic resonance allows characterisation of valve phenotype in patients with bicuspid aortic valves (BAVs). A raphe was identified in the majority of patients ( $n=90 ; 86 \%$ ). Among patients with raphe, 76 patients had fusion between the right and left cusps and 14 patients had fusion between the right and the non-coronary cusps. ${ }^{42}$ The fused right and non-coronary leaflet BAVs are the product of a morphogenetic defect that occurs before cardiac outflow tract septation and probably relies on an exacerbated nitric oxide-dependent epithelial-to-mesenchymal transformation. Fused right and left leaflet BAVs result from anomalous septation of the proximal portion of the cardiac outflow tract, probably caused by the distorted behaviour of neural crest cells. The two phenotypes are different aetiological entities and may rely on different genotypes. ${ }^{43}$ The prevalence of aortic root dilation in BAV patients is 32\% and $53 \%$ in their first-degree relatives (even with tricuspid aortic valves). Like patients with BAV, their first-degree relatives have a significantly lower aortic distensibility and greater aortic stiffness index than control subjects. Screening of first-degree relatives of patients with a bicuspid aortic valve by echocardiography should be considered for detection of aortic valve malforma- 
tion and dilated ascending aorta. ${ }^{44}$ Careful clinical follow-up of patients after successful resection of subaortic stenosis is required. Of 121 adults with subaortic stenosis, $23 \%$ had bicuspid valves and $21 \%$ had coarctation of the aorta. Seventy-nine per cent of the patients had a surgical resection of subaortic tissue. Valve surgery for AS was required in $26 \%$ and was more common in patients with concomitant BAV disease, coarctation of the aorta and supravalvular stenosis. Moderate to severe AR was present in $16 \%$ of patients. ${ }^{45}$

\section{Aortic disease}

Diastolic tenting of aortic leaflets is strongly related to the severity of functional AR in patients with ascending thoracic aortic aneurysms. A sinotubular junction/ annulus mismatch is significantly associated with diastolic leaflet tenting and valve regurgitation, independently of the aneurysm dimension. ${ }^{46}$ Aortic root dilatation and reduced aortic elasticity are common in patients with tetralogy of Fallot, in addition to minor degrees of AR and reduced left ventricular systolic function. Aortic wall pathology in patients with repaired tetralogy of Fallot may therefore represent an independent contributor to left ventricular dysfunction, as part of a multifactorial process. ${ }^{47}$ In patients with ascending aortic aneurysm (unassociated with aortitis or acute dissection), the aortic valve is congenitally malformed (unicuspid or bicuspid) in $98 \%$ of patients with AS, and in $60 \%$ of patients with AR. Among the patients with congenitally malformed valves, those with AR have a significantly greater likelihood of significant aortic medial elastic fibre loss than those with AS. Distinction between AS and AR is helpful in predicting loss of aortic medial elastic fibres in patients with ascending aortic aneurysms and aortic valve disease. ${ }^{48}$ Ninety-three patients with severe isolated calcific AS with a tricuspid aortic valve who also had moderate dilatation of the ascending aorta (diameter $50-59 \mathrm{~mm}$ ) underwent AVR only. During a follow-up of 15 years, no acute aortic events (rupture, dissection, pseudoaneurysm), or need for reoperation occurred. Furthermore, there was no substantial increase in aortic dimensions, suggesting that indications for concomitant aortic surgery in patients with moderate post-stenotic dilatation of the ascending aorta and a tricuspid aortic valve, may be viewed more leniently, particularly in the absence of connective tissue disorders. ${ }^{49}$ In a community cohort that included 416 consecutive patients with definite BAV diagnosed by echocardiography, followed up for $16 \pm 7$ years, the incidence of aortic dissection was low ( 2 out of 416 patients) but higher than in the general population. Of 384 patients without baseline aneurysms, 49 developed aneurysms at follow-up and the 25 -year rate of aortic surgery was $25 \%$. $^{50}$

Prompt diagnosis of acute aortic dissection saves lives. Echocardiography has a time-honoured role, and recent work suggests that contrast-enhanced as compared with conventional transthoracic imaging improves diagnostic sensitivity and specificity for aortic dissection from $73.7 \%$ to $86.8 \%(p<0.005)$ and from $71.2 \%$ to
$90.4 \%(p<0.05)$, respectively. Indeed, the diagnostic sensitivity and specificity of contrast-enhanced transthoracic imaging was similar to that of conventional transoesophageal echocardiography in the ascending aorta (93.3\% vs $95.6 \%$ and $97.6 \%$ vs $96.4 \%$, respectively) and in the arch ( $88.4 \%$ vs $93.0 \%$ and $95 . \%$ vs $98.82 \%$, respectively) and should be considered as an initial imaging modality in an emergency. ${ }^{51}$

\section{Mitral regurgitation}

Degenerative mitral regurgitation (MR) is often dynamic, and exercise-induced increases of MR severity are seen in one-third of patients, associated with changes in systolic pulmonary artery pressure and reduced symptom-free survival..$^{52}$ When MR is severe it may be associated with unilateral pulmonary oedema..$^{53}$

Improving the timing of surgery for degenerative MR based on predictors of outcome is an important topic. The left atrial index was shown to predict outcome in 492 patients in sinus rhythm with organic MR and should thus be incorporated into routine clinical practice for risk stratification and clinical decision-making. ${ }^{54}$ A recent study showed that in MR, owing to flail leaflets, a left ventricular end-systolic diameter $\geq 40 \mathrm{~mm}$ is independently associated with increased mortality for medically and surgically managed patients. Nevertheless, the left ventricular end-systolic dimension may provide a useful guide for the timing of surgery in these patients but because both asymptomatic and symptomatic patients were included, the findings need confirmation in symptomatically homogeneous cohorts..$^{55}$ In another study of 256 patients with organic MR referred for mitral valve surgery, baseline pulmonary artery systolic pressure predicted long-term postoperative survival with 8 -year survival rates of $58.6 \%$ and $86.6 \%$ for patients whose PA pressures were greater or less than $50 \mathrm{~mm} \mathrm{Hg}$, respectively $(p<0.0001) .^{56}$

As with other valvular pathologies, oxidative stress may be aetiologically important in MR. Thus, LV biopsy specimens taken during mitral valve repair surgery for isolated MR demonstrated that increased oxidative stress could cause lipofuscin deposition and cardiomyocyte myofibrillar degeneration..$^{57}$

The severity of MR seems to be an important determinant of left ventricular reverse remodelling after cardiac resynchronisation therapy when gains in LVEF and forward stroke volume are greatest for patients with improvement in total MR, intermediate for those with mild or no MR at baseline and least in those whose MR shows no improvement. ${ }^{58}$

Guideline indications for surgical intervention in patients with MR are often ignored by cardiologists and in a recent assessment of current practice, surgery was performed in only about $50 \%$ of cases despite the fact that guideline indications for intervention were present in many of the patients not receiving surgery. ${ }^{59}$ Among patients with guideline indications any delay in carrying out surgery may have important adverse consequences as reflected in a recent report where surgery at a median time of 0.42 months after listing was associated a 
lower hazard for death than for those who underwent later surgery at a median time of 8.75 months ( $H R=0.54$, $\mathrm{p}=0.039){ }^{60}$

In the study of Samad et al, mitral valve repair was independently associated with improved survival ( $H R=0.45, p=0.01) .{ }^{60}$ This has been shown in many other recent studies but an assessment of 'real-world' clinical practice based on 12255 mitral valve operations performed in the UK between 2004 and 2008 showed a national rate of only $51 \%$, and variability of $20 \%$ to $90 \%$ among different hospitals, which the authors likened to a "lottery of mitral valve repair surgery." ${ }^{61}$ This was emphasised further in a more recent analysis of the STS Adult Cardiac Surgery Database, which showed substantial variability in rates of mitral valve repair among individual surgeons, ranging from $0 \%$ to $100 \%$ (mean $41 \%$ ). The greatest variability in repair rates was seen among surgeons carrying out a low volume of procedures, with increased surgeon-level mitral volume being independently associated with an increased probability of mitral repair. ${ }^{62}$

\section{Experimental studies on the mechanism of mitral regurgitation}

Understanding the mechanism of valve adaptation provides a potential means of identifying new biological and surgical therapeutic targets. Anteroapical myocardial infarction (MI) with inferoapical extension can mechanically displace papillary muscles, causing MR despite the absence of basal and mid-inferior wall motion abnormalities. ${ }^{63}$ In a sheep model of inferior MI an epicardial patch to limit ventricular dilatation and MR resulted in a leaflet area at 3 months that was not significantly different from baseline values. In untreated sheep, mitral valve area increased over time as the left ventricular remodelled after inferior $\mathrm{MI}$, independently of systolic stretch but failed to compensate adequately for tethering to prevent MR. ${ }^{64}$ Management of severe ischaemic MR remains difficult with disappointing early and intermediate-term surgical results of valve repair. Posterior leaflet extension with annuloplasty of the mitral valve for severe type IIIb ischaemic regurgitation has been suggested to provide good early and intermediateterm competence of the mitral valve and functional status. ${ }^{65}$ In an experimental model, the papillary muscle tips in six adult sheep were retracted apically, short of producing $\mathrm{MR}$ - thus replicating the effects of tethering without confounding MI or turbulence. At 60 days, total diastolic mitral leaflet area increased by $17 \%$ and stretched mitral valves were 2.8 times thicker than normal with an increased spongiosa layer. Cellular changes suggest a reactivation of embryonic developmental pathways. ${ }^{66}$ It has been shown that mitral tenting leading to functional MR is mainly determined by tethering (displacement of papillary muscles) and pushing forces (increased left atrial pressure), independently of ventricular function, findings that emphasise the central role of left ventricular preload as a key determinant of functional MR. ${ }^{67}$ In patients with idiopathic dilated cardiomyopathy who underwent annuloplasty for functional MR, the postoperative distal mitral anterior leaf- let angle was the major determinant of recurrent functional MR. The preoperative distal mitral anterior leaflet angle was the best predictor of MR recurrence. Since posterior leaflet tethering is invariable after mitral annuloplasty, postoperative mitral competence is highly dependent on distal anterior leaflet mobility. ${ }^{68} \mathrm{~A}$ strong association between pre-existing hypertension and idiopathic mitral chordae tendineae rupture was described. However, it remains unclear whether prevention by hypertension control is feasible. ${ }^{69}$

\section{Tricuspid regurgitation}

The tricuspid valve is often called the forgotten valve, partly because data concerning the optimal timing of surgery in tricuspid regurgitation (TR) are limited.

During inspiration, a large increase in effective regurgitant orifice causes a notable increase in tricuspid regurgitant volume, despite a decline in regurgitant gradient. Effective regurgitant orifice changes are independently linked to inspiratory annular enlargement (decreased valvular coverage) and to inspiratory right ventricular (RV) shape widening with increased valvular tenting. These physiological insights are important for clinical evaluation of the severity of TR. ${ }^{70}$ Severe $\mathrm{TR}$, constrictive pericarditis and restrictive cardiomyopathy can all present with signs and symptoms of right heart failure and similar haemodynamic findings of elevation and equalisation of diastolic pressures at catheterisation. The haemodynamic findings at cardiac catheterisation in patients with severe, symptomatic TR are similar to those of constrictive pericarditis. Careful analysis of the relationship of the LV and RV diastolic pressures during respiration can help differentiate between the two entities. During inspiration, the difference between the LV and RV diastolic pressures widens in patients with TR but narrows in those with constrictive pericarditis. ${ }^{71}$ Of 69 consecutive patients undergoing surgery for isolated severe TR, seven (10.1\%) died before discharge. Of the remaining 62 patients, three died during follow-up and eight were readmitted owing to cardiovascular problems. RV end-systolic area $(p=0.006)$ and haemoglobin level $(p<0.001)$ were independent predictors of event-free survival. When early postoperative echocardiography variables were included, early postoperative RV fractional area change provided additional information for predicting long-term clinical events following corrective TR surgery. ${ }^{72}$ The overall incidence of late significant TR after successful left-sided valve surgery was 7.7\% (49/638). Age, female gender, rheumatic aetiology, atrial fibrillation and peak pressure gradient of TR at follow-up were independent factors associated with development of late significant TR. Patients who developed late significant TR showed a significantly lower 8-year clinical event-free survival rate $(76 \%$ vs $91 \%, p<0.001) . .^{73}$ After tricuspid annuloplasty, tenting angles of the three leaflets increase, whereas the annulus diameter decreases. Presurgical tenting volume and anteroposterior tricuspid annulus diameter are independent predictors of residual TR severity, and may help to identify patients at high risk for 
severe residual TR for whom tricuspid valve replacement may be considered. ${ }^{74}$ Tricuspid valve replacement for severe TR can be performed with an acceptable operative mortality if patients undergo surgery before the onset of advanced heart failure symptoms. Late mortality is associated with a high preoperative Charlson index, short right index of myocardial performance ratio and advanced New York Heart Association class. ${ }^{75}$

\section{Risk of non-cardiac surgery}

In a prospective cohort of 2054 patients undergoing elective major non-cardiac surgery, high preoperative NTproBNP or $\mathrm{C}$ reactive protein were strong, independent predictors of perioperative major cardiovascular events (MI, pulmonary oedema or cardiovascular death) in noncardiac surgery. The relative event-risk of highest versus lowest quartile was 5.2 for NT-proBNP $(p<0.001)$ and 3.7 for $C$ reactive protein $(p<0.001)$. The predictive power of the current clinical risk evaluation system might be strengthened by application of these biomarkers. ${ }^{76}$

\section{Endocarditis}

The high mortality of patients with endocarditis makes it an important focus of continuing clinical research. Blood culture-negative early prosthetic valve endocarditis exhibits specific aetiologies, and fungi are the most common pathogens identified. They should be investigated by molecular methods on surgical specimens and an antifungal drug might be added to the empirical treatment. ${ }^{77}$ Almost $50 \%$ of cases of coagulase-negative staphylococcal prosthetic valve endocarditis occur between 60 and 365 days after prosthetic valve implantation and are associated with a high rate of methicillin resistance and significant valvular complications. ${ }^{78}$ Increasing age is associated with less valvular impairment (insufficiency and perforation) and a more favourable microbiological profile in patients with left-sided infective endocarditis. However, the therapeutic approach differs depending on patient age because of the growing proportion of older patients who receive only medical treatment. Clinical course and hospital prognosis are worse in older patients because of an increased surgical mortality. ${ }^{79}$ Three independent risk factors obtained within $72 \mathrm{~h}$ of admission for left-sided infective endocarditis (Staphylococcus aureus, heart failure and periannular complications) predict in-hospital mortality or the need for urgent surgery. ${ }^{80}$ Bicuspid aortic valve infective endocarditis accounts for $16 \%$ of cases of definite native aortic valve endocarditis and is associated with a perivalvular aortic abscess in half of the cases. The presence of a bicuspid aortic valve $(H R=3.79, p<0.001)$ is independently predictive of abscess formation, and early surgery is often required. ${ }^{81}$ There is now evidence that preoperative coronary angiography can be performed with low risk in selected patients with aortic valve endocarditis. A recent study reported no embolic events, no increase in in-hospital mortality $(p=0.80)$ and no worsening of renal function $(p=0.93) .{ }^{82}$ By performing preoperative coronary angiography in patients with cardiovascular risk factors, those with significant coronary disease can be considered for bypass at the time of valve surgery. In a multinational cohort of 1552 patients with native valve endocarditis, early surgery was associated with a significant reduction in mortality compared with medical treatment $(12.1 \%$ vs $20.7 \%){ }^{83}$ Strategies of early surgery within 7 days, at the discretion of the attending doctor, and of conventional management in patients with left-sided native-valve were compared in another study. During the initial hospitalisation, there were no embolic events and two in-hospital deaths in the surgical group $(n=64)$ and 14 embolic events and two in-hospital deaths in the conventional group $(n=68)$. The 5 -year event-free survival rate was significantly better in the surgical group $(93 \pm 3 \%)$ than in the conventional group $(73 \pm 5 \%, p=0.0016) .{ }^{84}$ Although the timing of surgery was not randomly allocated, the data suggest that early surgery, when feasible, may offer important advantages to the patient.

\section{Valve surgery}

\section{Ross procedure}

The controversy surrounding the Ross procedure is highlighted by four studies. In a randomised study 216 patients received either an autograft or a homograft aortic root replacement. At 10 years, four patients in the autograft group and 15 in the homograft group died. Actuarial survival at 10 years was $97 \%$ in the autograft group versus $83 \%$ in the homograft group. ${ }^{85} \mathrm{MRI}$ of 45 patients at a median interval of 8 years postoperatively demonstrated minor autograft and homograft dysfunction in the majority of cases, associated with good ventricular function and exercise capacity. ${ }^{86}$ Another study compared the outcome of the Ross procedure (918 patients) with that of 406 mechanical valve recipients under optimal self-management anticoagulation treatment; there was no late survival difference in the first postoperative decade between the two groups. Survival in these selected young adult patients closely resembles that of the general population, possibly as a result of optimised anticoagulation self-management, timing of surgery and patient selection. ${ }^{87} \mathrm{~A}$ less optimistic picture was depicted by a study emphasising the broad spectrum of complex reoperations that may be required relatively often after the Ross procedure. The four most common indications for reoperation $(n=56)$ were isolated autograft (neoaortic) regurgitation in $20 \%$, isolated pulmonary conduit regurgitation/stenosis in $16 \%$, combined autograft regurgitation/dilatation in $14 \%$, and combined autograft regurgitation and pulmonary conduit regurgitation/stenosis in $11 \%$. Patients and family members considering the procedure should be informed of the potential for associated morbidity should reoperation be necessary. ${ }^{88}$

\section{Predictors of postoperative outcome after aortic valve replacement}

A 6 min walk test was found to be safe and feasible to carry out in patients with severe AS before AVR, and provides potentially important functional and prognostic information for clinical assessment and the Euros- 
core risk score. At 12 months, the rate of death, $\mathrm{MI}$ or stroke was $13 \%$ in patients walking $<300 \mathrm{~m}$ as compared with $4 \%$ in those who walked $\geq 300 \mathrm{~m}(\mathrm{p}=0.017) .{ }^{89}$ Physical quality of life 1 year after valve surgery was predicted by baseline physical quality of life and walk performance. Postoperative mental quality of life was predicted by depression, baseline mental quality of life and age, with age having a positive effect, suggesting that treating depression and modifying negative illness beliefs preoperatively, may improve outcome. ${ }^{90}$ Women referred for AVR were found to be older and more symptomatic. Although operative and long-term mortality were not increased, women remained in a more symptomatic stage. ${ }^{91}$ Patients undergoing renal transplantation requiring valve replacement have high mortality rates (approximately 20\%/year). Two-year survival estimates were comparable for patients receiving a tissue valve $(61.5 \%)$ or a non-tissue-valve $(59.5 \%, p=0.30) .{ }^{92}$

\section{Impact of age on valve surgery}

Patients aged 55-70 years undergoing AVR either with mechanical or bioprosthetic valves had similar 13-year rates of survival, thromboembolism, bleeding, endocarditis and major adverse prosthesis-related events. However, patients with bioprosthetic valves had a significantly higher risk of valve failure and reoperation. ${ }^{93}$ Using microsimulation of survival and valve-related outcomes from 5470 AVR procedures, it was found that bioprostheses may be implanted selectively in patients as young as 56 without significant adverse effects on life expectancy, although event-free survival remains significantly lower with bioprostheses for patients up to age of $63 .{ }^{94}$ Increasing numbers of the very elderly are undergoing AVR procedures. Late survival of 2890 consecutive elderly patients ( $\geq 70$ years) who underwent AVR was influenced by age and preoperative comorbidities; the $33 \%$ in the lowest risk tertile had an overall survival similar to that of the age- and sex-matched general population. Structural deterioration of aortic bioprostheses was rare and there was no conclusive evidence that valve type affected survival in these patients. ${ }^{95}$ Also in octogenarians, survival after AVR is favourable even with concomitant bypass surgery and more than half of the patients survive for more than 6 years after their surgery. Median survival for patients undergoing isolated AVR was 6.8 years for those aged $80-84$ years $(n=419)$ and 6.2 years for those aged $\geq 85$ years $(n=156)$, similar to the life expectancy of the general population. ${ }^{96}$

\section{Patient-prosthesis-mismatch}

Patient-prosthesis-mismatch (PPM) was identified in $40 \%$ of 645 patients after AVR in a study in which indexed effective orifice area was obtained by postoperative echocardiography and modelled as a continuous variable. After a median follow-up of 2.35 years, $92.1 \%$ of the patients were alive. Cardiac death among patients with a smaller indexed effective orifice area was significantly increased $(H R=0.32, p=0.022) .{ }^{97}$ Among
2576 patients who survived AVR and after adjustment for other risk factors, severe PPM was associated with increased late overall mortality $(H R=1.38 ; p=0.03)$ and cardiovascular mortality ( $\mathrm{HR}=1.63 ; \mathrm{p}=0.0006)$. Moderate PPM was a predictor of mortality in patients with LV ejection fraction $<50 \%(H R=1.21 ; p=0.01)$, but not in patients with preserved LV function. ${ }^{98}$ The presence of PPM after AVR attenuates postoperative mitral regurgitation changes, mainly in patients with organic mitral regurgitation. ${ }^{99}$ In 564 patients receiving an aortic valve bioprosthesis, structural valve deterioration was diagnosed in 40 patients (7\%). Stenosis-type structural valve deterioration $(n=24)$ was found to be an early, PPM-related, and thus preventable, phenomenon. Regurgitation-type structural valve deterioration $(n=16)$ is a timedependent, non-specific wear of bioprosthetic valves, which is not related to PPM. ${ }^{100}$ In a multicentre series of 1006 mechanical and bioprosthetic mitral valves, PPM was not associated with worse early outcomes or worse mid-term survival. ${ }^{101}$

\section{Mitral valve surgery}

Elective mitral valve (MV) repair can be performed with a low operative mortality and good long-term outcomes in selected octogenarians with degenerative mitral disease, and is associated with better long-term survival than mitral replacement. Overall 90-day mortality of consecutive octogenarians who underwent MV repair was significantly lower (18.9\%) than for MV replacement (31.6\%). Adjusted 1-, 3- and 5-year survival for patients undergoing MV repair was $71 \pm 3,61 \pm 4$ and $59 \pm 4 \%$, respectively, compared with $56 \pm 5,50 \pm 6$ and $45 \pm 6 \%$ for patients undergoing MV replacement $(p=0.046)$. The survival benefit associated with surgery for non-degenerative disease is more questionable. ${ }^{102}$

Of 402 patients with atrial fibrillation-associated MV disease who underwent MV replacement with a mechanical prosthesis, 159 underwent a concomitant Maze procedure. At a median follow-up of 63.1 months, patients who had undergone the Maze procedure were at significantly lower risk of thromboembolic events ( $H R=0.26 ; p=0.041)$ and were at comparable risk of death and cardiac death as patients who underwent MV replacement alone. ${ }^{103}$

In 370 patients with ischaemic MR, after adjusting for other risk factors and propensity score, the type of procedure (MV repair vs MV replacement) was not an independent predictor of either operative or overall mortality. ${ }^{104}$ One hundred and thirty-five patients with ischaemic heart disease and moderate ischaemic MR underwent isolated coronary artery bypass graft surgery. At 1 year, 57 patients had no or mild ischaemic MR, whereas 64 patients had failed to improve. Large extent ( $\geq 5$ segments) of viable myocardium ( $O R=1.45 ; p<0.001)$ and absence ( $<60 \mathrm{~ms}$ ) of dyssynchrony ( $O R=1.49$; $p<0.001$ ) were independently associated with improvement in ischaemic MR. ${ }^{105}$

Combined mitral and tricuspid valve repair in rheumatic disease showed satisfactory early results in 153 consecutive patients (mean age 46 years) who under- 
went combined mitral and tricuspid valve repair for rheumatic disease. However, long-term results were poor because of high mortality and a high number of valve-related reoperations. Survival-rate was $74.4 \%$ at 10 years and $57.0 \%$ at 15 years. At 20 years, the rate of freedom from reoperation was $48.5 \% .{ }^{106}$

\section{Anticoagulation}

Despite the use of intravenous unfractionated heparin, the rate of early thromboembolism in a series of 300 consecutive mechanical valve replacements remained significant. Early thromboembolism within 30 days of surgery occurred in 22 patients (14.8\%) after a mitral or double mechanical valve replacement and in two patients (1.3\%) after an aortic mechanical valve replacement $(p=0.005)$. Inappropriate anticoagulation on day 3 was significantly associated with early thromboembolism, suggesting that early effective anticoagulation is required after mitral mechanical valve replacement. ${ }^{107}$

\section{Prosthetic valve thrombosis}

A randomised controlled trial comparing an accelerated infusion with the conventional infusion of streptokinase was performed in 120 patients with a first episode of left-sided prosthetic valve thrombosis, recruited over a 2.5-year period at a single centre in India. The large patient number underlines the massive burden of prosthetic valve thrombosis in developing countries. Fibrinolytic therapy with streptokinase is less efficacious than previously believed, with a complete clinical response in 70 of 120 patients. The accelerated streptokinase infusion is no better than standard infusion for left-sided prosthetic valve thrombosis. ${ }^{108}$

\section{Transcatheter aortic valve implantation}

\section{Patient selection}

Objective parameters to assess interventional risk and thus to identify patients at high risk who would benefit from percutaneous procedures are needed. For this, reliable risk scores that predict surgical mortality would be helpful. While the EuroSCORE still successfully discriminates high-risk patients undergoing surgical aortic valve replacement, it has become increasingly uncalibrated with absolute risk, resulting in overestimation of 30-day mortality. ${ }^{109}$ The limitations of risk scores are also commented upon in a recent ESC position paper on risk assessment before interventions in patients with valvular disease. ${ }^{110}$

\section{Imaging of the aortic annulus and of tran- scatheter aortic valve deployment}

Adequate sizing of the aortic annulus is essential in order to assess the suitability of a patient for a transcatheter aortic valve implantation (TAVI) procedure and the choice of the prosthesis size. By CT an ellipsoid shape of the aortic valve annulus with a larger coronal than sagittal diameter (25.1 \pm 2.4 vs $22.9 \pm 2.0 \mathrm{~mm}, \mathrm{p}<0.001)$ was measured. ${ }^{111} 2 \mathrm{D}$ imaging techniques underestimate aortic annulus diame- ters and 3D imaging techniques are now recommended for this purpose. 3D transoesophageal echocardiography (TOE) provides measurements of aortic annulus diameters similar to those obtained by CT. ${ }^{112}$ While measurements using transthoracic echocardiography, TOE and CT are close but not identical, a strategy based on TOE measurements provides good clinical results. ${ }^{113}$ The presence of LV dysfunction, male gender and larger body surface area are independent determinants of a larger aortic annular diameter. ${ }^{114} \mathrm{By} \mathrm{CT}$, incomplete and non-uniform expansion of the CoreValve frame can be identified: undersizing and incomplete apposition is commonly present. ${ }^{115}$ Non-circular deployment of the prosthesis is found in $14 \%$ of patients. Moderate postprocedural aortic regurgitation is seen in $11 \%$ patients and is associated with larger aortic valve annulus, more calcified native valves and less favourable prosthesis deployment. ${ }^{111}$

\section{Establishing a transcatheter aortic valve implantation programme}

To provide consistency across studies that can facilitate the evaluation of this new catheter-based treatment, and improve the quality of clinical research, the Valve Academic Research Consortium proposed standardised consensus definitions for important clinical end points in TAVI investigations. ${ }^{116}$ Retrospective examination of adherence to patient selection criteria identified an "off-label" use of TAVI beyond pre-market label indications in 42 of 63 patients. ${ }^{117}$ This study highlights the challenges encountered in the rollout phase of a new technology. The ability to offer either transfemoral or transapical aortic valve implantation, using a standardised approach, with the transfemoral approach as the first option, may expand the scope of the treatment of AS in high-risk patients and provide satisfactory 1-year results. ${ }^{18}$ Introduction of a TAVI service does not appear to have a negative effect on conventional surgical activity. One study reported a $37 \%$ increase in surgical AVR in the 2 years after introduction of TAVI in a dedicated centre, compared with an $8 \%$ increase nationally $(p<0.001) .{ }^{119}$

\section{Feasibility of transcatheter aortic valve implantation}

An early single-centre experience established the feasibility of TAVI, both by the transfemoral approach $(n=168)$, with a success rate of $94.1 \%$ and 1 -year survival of $74 \%,{ }^{120}$ and by the transapical approach $(n=100)$, with a success rate of $97 \%$ and 1-year survival of $73 \%{ }^{121}$ Data for an extended follow-up period of 3 years have been reported, and no cases of structural valvular deterioration, stent fracture, deformation, or valve migration occurred. ${ }^{122}$

\section{Procedural outcome of transcatheter aortic val-} ve implantation: registries and randomised trials

Patients with severe AS, considered unsuitable candidates for surgery $(n=358)$, were randomly assigned to standard treatment (including balloon aortic valvuloplasty) or transfemoral TAVI using the Edwards SAPIEN 
valve in the PARTNER B trial. TAVI, as compared with standard treatment, significantly reduced the rates of death from any cause $(30.7 \%$ vs $50.7 \%)$, the composite end point of death from any cause or repeat hospitalisation (42.5\% vs $71.6 \%$ ) and cardiac symptoms, despite a higher incidence of major strokes (5.0\% vs $1.1 \%)$ and major vascular events (16.2\% vs $1.1 \%) .{ }^{123}$ This study also nicely depicts the contemporary natural history of severe symptomatic AS.

The PARTNER A trial randomised 699 high-risk patients with severe AS to undergo TAVI or surgical AVR. Transcatheter and surgical procedures for AVR were associated with similar rates of survival at 1 year $(24.2 \%$ vs $26.8 \%$, respectively), although there were important differences in periprocedural risks, with vascular complications more common in the TAVI group ( $11.0 \%$ vs $3.2 \%, p<0.001$ ) and more frequent major bleeding and new-onset atrial fibrillation with surgery. ${ }^{124}$ One-year survival in the SOURCE registry $(n=1038)$ was $76.1 \%$ (72.1\% for transapical and $81.1 \%$ for transfemoral TAVI). Interestingly, causes of death were mainly non-cardiac in $49.2 \%$ (cardiac in $25.1 \%$, and unknown in $25.7 \%$ ) with pulmonary complications $(23.9 \%)$, renal failure $(12.5 \%)$, cancer $(11.4 \%)$ and stroke $(10.2 \%)$ as the most common non-cardiac causes of death. ${ }^{125}$ These data reflect the importance of associated comorbidities. Several other multicentre registries (including the PARTNER EU registry, the German TAVI registry, the French FRANCE registry, an Italian and a Canadian registry) have confirmed the feasibility of the procedure in high-risk or unoperable patients with AS with good procedural success, haemodynamic results and mid-term outcomes. ${ }^{126-131}$

\section{Specific predictors of outcome for transcathe- ter aortic valve implantation}

Mean transprosthetic gradients were lower for TAVI $(10 \pm 4 \mathrm{~mm} \mathrm{Hg})$ than for stented $(13 \pm 5 \mathrm{~mm} \mathrm{Hg})$ and stentless $(14 \pm 6 \mathrm{~mm} \mathrm{Hg}$ ) bioprostheses $(p<0.001)$. Severe PPM was significantly lower with TAVI (6\%) than with a bioprosthesis (24\%; $p=0.007) .{ }^{132}$ TAVI can be successfully carried out in most patients (34/35) with a small aortic annulus diameter $<20 \mathrm{~mm}$, with severe PPM occurring in two patients only, and gradients remaining low in the other patients. ${ }^{133}$ It may also provide an interesting alternative to AVR in patients with depressed LV systolic function, where it is found to be associated with better LVEF recovery than conventional AVR (change in LVEF $14 \pm 15 \%$ vs $7 \pm 11 \%$; $p=0.005$ ), although these patients were older and had more significant comorbidities. At 1 year, $58 \%$ of TAVI patients had a normalisation of LVEF (>50\%) as opposed to $20 \%$ in the AVR group. ${ }^{134}$ Pre-procedural functional performance status (assessed by the Karnofsky index) predicts the in-hospital procedural success rates and $\mathrm{MI}$ and stroke rates after TAVI. ${ }^{135}$ Thirty days after TAVI quality of life and 6 min walk distance improved significantly while BNP levels declined. ${ }^{136}$ Acute kidney injury occuring in $11.7 \%$ of patients after TAVI, is associated with a greater than fourfold increase in the risk of postoperative mortality. Hypertension, chronic obstructive pulmonary disease and blood transfusion are predictive factors of acute kidney injury. ${ }^{137}$ TAVI was systematically associated with some degree of myocardial injury in the majority of patients. The greater degree of myocardial injury seen with the transapical approach and baseline renal dysfunction is associated with less improvement in LVEF and a greater cardiac mortality at follow-up. ${ }^{138}$ Significant AR was reported to occur in $17.2 \%$ of patients and is associated with significantly higher in-hospital death rates $(15.1 \%$ vs $6.7 \%)$, rates of low cardiac output and respiratory failure. ${ }^{139}$ For the CoreValve a greater likelihood of significant AR was found with a greater angle of LV outflow tract to ascending aorta (OR=1.24, $p=0.001) .{ }^{140}$ New cerebral ischaemic lesions can be detected by diffusion-weighted MRI in between $68 \%$ and $84 \%$ of patients after TAVI. ${ }^{141-143}$ These lesions were usually multiple (1 to 19 per patient) and dispersed in both hemispheres in a pattern suggesting cerebral embolisation. These foci were not associated with apparent neurological events or measurable deterioration of neurocognitive function. The rate of major stroke was in the range of $3.3 \%$ to $3.8 \% .^{124141} 143$

\section{Transcatheter valve in a valve implantation}

The concept of a valve in valve implantation in a degenerated aortic bioprosthesis was successful in 24 patients, with a decline of mean transaortic gradient from $45.4 \pm 14.8$ to $10.1 \pm 4.2 \mathrm{~mm} \quad \mathrm{Hg}$. Major adverse cerebrovascular and cardiac event rates were $0 \%$ and $14.1 \%$, at 30 days and 12 months, respectively. ${ }^{144}$ Valve-in-valve implantations was also performed in 24 high-risk patients with bioprostheses in different positions (aortic, $n=10$; mitral, $n=7$; pulmonary, $n=6$; or tricuspid, $n=1$ ). Implantation was successful, with immediate restoration of satisfactory valve function in all but one patient. Thirty-day mortality was $4.2 \%$. Mortality was related primarily to inexperience of the surgeon in this high-risk procedure. $^{145}$

\section{Transcatheter pulmonary valve implantation}

Transcatheter pulmonary valve implantation of the Melody valve was shown to be feasible in three series including 14, 102 and 136 patients with dysfunctional right ventricular outflow tract conduits, respectively. ${ }^{146-148}$ One death due to compression of the left coronary artery ${ }^{147}$ and one death from intracranial haemorrhage after coronary artery dissection occurred. ${ }^{148}$ The studies consistently showed a significant reduction of the right ventricular outflow tract gradient, a reduction of right ventricular volume and of pulmonary regurgitation. Freedom from Melody valve dysfunction or reintervention was $93.5 \pm 2.4 \%$ at 1 year. A higher right ventricular outflow tract gradient at discharge $(p=0.003)$ and younger age $(p=0.01)$ were associated with shorter freedom from dysfunction. ${ }^{148}$ The incidence of stent fractures was $5 \% .{ }^{147}$ Pre-stenting with a bare metal stent is associated with a lower risk of developing percutane- 
ous pulmonary valve implantation stent fractures $(H R=0.35, p=0.024) .{ }^{149}$ While short-term follow-up data are encouraging, longer-term information is required to determine if this form of palliation has a significant impact on management strategies.

\section{Transcatheter tricuspid valve implantation}

The first human experience of successful percutaneous tricuspid valve implantation (Melody valve) in 15 patients with significant stenosis and/or regurgitation of a bioprosthetic tricuspid valve or a right atrium-toright ventricle conduit was reported with a reduction of the mean tricuspid gradient from 12.9 to $3.9 \mathrm{~mm} \mathrm{Hg}$ $(p<0.01)$ and only mild or no residual regurgitation. ${ }^{150}$

\section{Percutaneous mitral valve therapies}

The challenges when implementing new techniques include patient selection, an adequate setting, and continuous evaluation, and are well summarised by the NICE guidelines for percutaneous mitral valve repair. ${ }^{151} \mathrm{After}$ the initial EVEREST Trial, which was a feasibility study performed in 23 patients, ${ }^{152}$ the randomised EVEREST II Trial compared the outcome of percutaneous implantation of a clip (the MitraClip) that grasps and approximates the edges of the mitral leaflets to conventional mitral valve surgery in 279 patients with moderate or severe MR. At 12 months, the following end points were seen for patients in the percutaneous-repair group and in the surgery group, respectively: death, $6 \%$ in each group; surgery for mitral-valve dysfunction, $20 \%$ versus $2 \%$; and grade $3+$ or $4+$ MR, $21 \%$ versus $20 \%$. At 12 months, both groups had improved LV size, New York Heart Association functional class and quality-of-life measures, as compared with baseline. ${ }^{153}$ From a haemodynamic perspective, successful MitraClip implantation in 107 patients resulted in an immediate and significant improvement in forward stroke volume, cardiac output and LV loading conditions. There was no evidence of a low cardiac output state after MitraClip treatment for MR. ${ }^{154}$ Histological evaluation of 67 explanted MitraClip devices showed that mechanical integrity of the device was maintained. Four phases of physiological healing include platelet and fibrin deposition, inflammation, granulation tissue and, finally, fibrous encapsulation. At long term, device fibrous encapsulation with extension over adjacent mitral leaflets and tissue bridge formation adds structural stability. ${ }^{155}$ The feasibility of percutaneous mitral annuloplasty through the coronary sinus with the CARILLON Mitral Contour System was shown in 30 of 48 patients, with functional improvement and a major adverse event rate of $13 \%$ at 30 days. ${ }^{156}$

\section{Percutaneous balloon mitral valvuloplasty}

An increasing preprocedural MR severity was associated with reduced percutaneous balloon mitral valvuloplasty (PMV) success in a large study that included 876 patients (no MR, 75\%; 1+ MR, 65\%; 2+ MR, 44\%; $p<0.0001)$, increased in-hospital mortality $(0.6 \%$ vs $2.8 \%$ vs $4.9 \%$, respectively; $p=0.007$ ). Patients with moderate preprocedural MR, in particular, appear to have suboptimal short- and long-term outcomes, requiring careful monitoring and early referral for mitral valve surgery, when appropriate. ${ }^{157}$ After successful PMV, left atrial volume and percentage change of the left atrial volume immediately after PMV emerged as independent predictors of event-free survival together with age, pre-PMV tricuspid regurgitation and post-PMV mitral valve area. Ten-year survival was $93 \%$ in patients with smaller left atria before PMV $\left(\leq 72 \mathrm{ml} / \mathrm{m}^{2}\right)$, whereas it was only $60 \%$ in those with larger left atria $\left(>72 \mathrm{ml} / \mathrm{m}^{2}\right) .{ }^{158}$ After successful PMV $(n=329)$ an immediate post-PMV mitral valve area $\geq 1.8 \mathrm{~cm}^{2}$ predicted both restenosis and clinical event-free survival. ${ }^{159}$

\section{References}

1. d'Arcy JL, Prendergast BD, Chambers JB, et al. Valvular heart disease: the next cardiac epidemic. Heart 2011;97:91-3.

2. Stritzke J, Linsel-Nitschke P, Markus MR, et al. Association between degenerative aortic valve disease and long-term exposure to cardiovascular risk factors: results of the longitudinal populationbased KORA/MONICA survey. Eur Heart J 2009;30:2044-53.

3. Akahori $H$, Tsujino T, Naito $Y$, et al. Intraleaflet haemorrhage is associated with rapid progression of degenerative aortic valve stenosis. Eur Heart J 2011;32:888-96.

4. Antonini-Canterin F, Leiballi E, Enache R, et al. Hydroxymethylglutaryl coenzyme-a reductase inhibitors delay the progression of rheumatic aortic valve stenosis a long-term echocardiographic study. J Am Coll Cardiol 2009;53:1874-9.

5. Chan KL, Teo K, Dumesnil JG, et al. Effect of Lipid lowering with rosuvastatin on progression of aortic stenosis: results of the aortic stenosis progression observation: measuring effects of rosuvastatin (ASTRONOMER) trial. Circulation 2010;121:306-14.

6. Monin JL, Lancellotti P, Monchi M, et al. Risk score for predicting outcome in patients with asymptomatic aortic stenosis. Circulation 2009;120:69-75.

7. Rosenhek R, Zilberszac R, Schemper M, et al. Natural history of very severe aortic stenosis. Circulation 2010;121:151-6.

8. Lancellotti P, Donal E, Magne J, et al. Risk stratification in asymptomatic moderate to severe aortic stenosis: the importance of the valvular, arterial and ventricular interplay. Heart 2010;96:1364-71.

9. Kang DH, Park SJ, Rim JH, et al. Early surgery versus conventional treatment in asymptomatic very severe aortic stenosis. Circulation 2010;121:1502-9.

10. Marechaux S, Hachicha Z, Bellouin A, et al. Usefulness of exercise-stress echocardiography for risk stratification of true asymptomatic patients with aortic valve stenosis. Eur Heart J 2010;31:1390-7.

11. Rajani R, Rimington $\mathrm{H}$, Chambers JB. Treadmill exercise in apparently asymptomatic patients with moderate or severe aortic stenosis: relationship between cardiac index and revealed symptoms. Heart 2010;96:689-95.

12. Hachicha Z, Dumesnil JG, Pibarot P. Usefulness of the valvuloarterial impedance to predict adverse outcome in asymptomatic aortic stenosis. J Am Coll Cardiol 2009;54:1003-11.

13. Dweck MR, Joshi S, Murigu T, et al. Midwall fibrosis is an independent predictor of mortality in patients with aortic stenosis. J Am Coll Cardiol 2011;58:1271-9.

14. Ng AC, Delgado V, Bertini M, et al. Alterations in multidirectional myocardial functions in patients with aortic stenosis and preserved ejection fraction: a two-dimensional speckle tracking analysis. Eur Heart J 2011;32:1542-50.

15. Delgado V, Tops LF, van Bommel RJ, et al. Strain analysis in patients with severe aortic stenosis and preserved left ventricular ejection fraction undergoing surgical valve replacement. Eur Heart J 2009;30:3037-47. 
16. Cramariuc D, Gerdts E, Davidsen ES, et al. Myocardial deformation in aortic valve stenosis: relation to left ventricular geometry. Heart 2010;96:106-12.

17. Cioffi G, Faggiano P, Vizzardi E, et al. Prognostic effect of inappropriately high left ventricular mass in asymptomatic severe aortic stenosis. Heart 2011;97:301-7.

18. Stewart RA, Kerr AJ, Whalley GA, et al. Left ventricular systolic and diastolic function assessed by tissue Doppler imaging and outcome in asymptomatic aortic stenosis. Eur Heart J 2010;31:2216-22.

19. Schueler R, Hammerstingl C, Sinning JM, et al. Prognosis of octogenarians with severe aortic valve stenosis at high risk for cardiovascular surgery. Heart 2010;96:1831-6.

20. Ben-Dor I, Pichard AD, Gonzalez MA, et al. Correlates and causes of death in patients with severe symptomatic aortic stenosis who are not eligible to participate in a clinical trial of transcath eter aortic valve implantation. Circulation 2010;122:S37-42.

21. Aksoy O, Yousefzai R, Singh D, et al. Cardiogenic shock in the setting of severe aortic stenosis: role of intra-aortic balloon pump support. Heart 2011;97:838-43.

22. Tribouilloy C, Levy F, Rusinaru D, et al. Outcome after aortic valve replacement for low-flow/low-gradient aortic stenosis without contractile reserve on dobutamine stress echocardiography. J Am Coll Cardiol 2009;53:1865-73.

23. Cueff C, Serfaty JM, Cimadevilla C, et al. Measurement of aortic valve calcification using multislice computed tomography: correlation with haemodynamic severity of aortic stenosis and clinical implication for patients with low ejection fraction. Heart 2011;97:721-6.

24. Minners J, Allgeier M, Gohlke-Baerwolf C, et al. Inconsistent grading of aortic valve stenosis by current guidelines: haemodynamic studies in patients with apparently normal left ventricular function. Heart 2010;96:1463-8.

25. Jander N, Minners J, Holme I, et al. Outcome of patients with low-gradient "severe" aortic stenosis and preserved ejection fraction. Circulation 2011;123:887-95.

26. Herrmann S, Stork S, Niemann M, et al. Low-gradient aortic valve stenosis myocardial fibrosis and its influence on function and outcome. J Am Coll Cardiol 2011;58:402-12.

27. Linefsky JP, O’Brien KD, Katz R, et al. Association of serum phosphate levels with aortic valve sclerosis and annular calcification: the cardiovascular health study. J Am Coll Cardiol 2011;58:291-7.

28. Nagy E, Andersson DC, Caidahl K, et al. Upregulation of the 5-lipoxygenase pathway in human aortic valves correlates with severity of stenosis and leads to leukotriene-induced effects on valvular myofibroblasts. Circulation 2011;123:1316-25.

29. El-Hamamsy I, Balachandran K, Yacoub MH, et al. Endotheliumdependent regulation of the mechanical properties of aortic valve cusps. J Am Coll Cardiol 2009;53:1448-55.

30. Matsumoto Y, Adams V, Walther C, et al. Reduced number and function of endothelial progenitor cells in patients with aortic valve stenosis: a novel concept for valvular endothelial cell repair. Eur Heart J 2009;30:346-55.

31. Aikawa E, Aikawa M, Libby P, et al. Arterial and aortic valve calcification abolished by elastolytic cathepsin S deficiency in chronic renal disease. Circulation 2009;119:1785-94.

32. Matsumoto Y, Adams V, Jacob S, et al. Regular exercise training prevents aortic valve disease in low-density lipoprotein-receptor-deficient mice. Circulation 2010;121:759-67.

33. Speidl WS, Cimmino G, Ibanez B, et al. Recombinant apolipoprotein A-I Milano rapidly reverses aortic valve stenosis and decreases leaflet inflammation in an experimental rabbit model. Eur Heart J 2010;31:2049-57.

34. Miller JD, Weiss RM, Serrano KM, et al. Lowering plasma cholesterol levels halts progression of aortic valve disease in mice. Circulation 2009;119:2693-701.

35. Falcao-Pires I, Hamdani N, Borbely A, et al. Diabetes mellitus worsens diastolic left ventricular dysfunction in aortic stenosis through altered myocardial structure and cardiomyocyte stiffness. Circulation 2011;124:1151-9.

36. Sampat U, Varadarajan P, Turk R, et al. Effect of beta-blocker therapy on survival in patients with severe aortic regurgitation results from a cohort of 756 patients. J Am Coll Cardiol 2009;54:452-7.
37. Pai RG, Varadarajan P. Prognostic implications of mitral regurgitation in patients with severe aortic regurgitation. Circulation 2010;122:S43-7.

38. Kamath AR, Varadarajan $P$, Turk R, et al. Survival in patients with severe aortic regurgitation and severe left ventricular dysfunction is improved by aortic valve replacement: results from a cohort of 166 patients with an ejection fraction $<$ or $=35 \%$. Circulation 2009;120:S134-8.

39. Villari B, Sossalla S, Ciampi Q, et al. Persistent diastolic dysfunction late after valve replacement in severe aortic regurgitation. Circulation 2009;120:2386-92.

40. Aicher D, Kunihara T, Abou Issa O, et al. Valve configuration determines long-term results after repair of the bicuspid aortic valve. Circulation 2011;123:178-85.

41. de Kerchove L, Boodhwani M, Glineur D, et al. Effects of preoperative aortic insufficiency on outcome after aortic valve-sparing surgery. Circulation 2009;120:S120-6.

42. Buchner S, Hulsmann M, Poschenrieder F, et al. Variable phenotypes of bicuspid aortic valve disease: classification by cardiovascular magnetic resonance. Heart 2010;96:1233-40.

43. Fernandez B, Duran AC, Fernandez-Gallego T, et al. Bicuspid aortic valves with different spatial orientations of the leaflets are distinct etiological entities. J Am Coll Cardiol 2009;54:2312-18.

44. Biner S, Rafique AM, Ray I, et al. Aortopathy is prevalent in relatives of bicuspid aortic valve patients. J Am Coll Cardiol 2009;53:2288-95.

45. Laksman ZW, Silversides CK, Sedlak T, et al. Valvular aortic stenosis as a major sequelae in patients with pre-existing subaortic stenosis changing spectrum of outcomes. J Am Coll Cardiol 2011;58:962-5.

46. La Canna G, Maisano F, De Michele L, et al. Determinants of the degree of functional aortic regurgitation in patients with anatomically normal aortic valve and ascending thoracic aorta aneurysm. Transoesophageal Doppler echocardiography study. Heart 2009;95:130-6.

47. Grotenhuis HB, Ottenkamp J, de Bruijn L, et al. Aortic elasticity and size are associated with aortic regurgitation and left ventricular dysfunction in tetralogy of Fallot after pulmonary valve replacement. Heart 2009;95:1931-6.

48. Roberts WC, Vowels TJ, Ko JM, et al. Comparison of the structure of the aortic valve and ascending aorta in adults having aortic valve replacement for aortic stenosis versus for pure aortic regurgitation and resection of the ascending aorta for aneurysm. Circulation 2011;123:896-903.

49. Gaudino M, Anselmi A, Morelli M, et al. Aortic expansion rate in patients with dilated post-stenotic ascending aorta submitted only to aortic valve replacement long-term follow-up. J Am Coll Cardiol 2011;58:581-4.

50. Michelena HI, Khanna AD, Mahoney D, et al. Incidence of aortic complications in patients with bicuspid aortic valves. JAMA 2011;306:1104-12.

51. Evangelista A, Avegliano G, Aguilar R, et al. Impact of contrastenhanced echocardiography on the diagnostic algorithm of acute aortic dissection. Eur Heart J 2010;31:472-9.

52. Magne J, Lancellotti P, Pierard LA. Exercise-induced changes in degenerative mitral regurgitation. J Am Coll Cardiol 2010;56:300-9.

53. Attias D, Mansencal N, Auvert B, et al. Prevalence, characteristics, and outcomes of patients presenting with cardiogenic unilateral pulmonary edema. Circulation 2010;122:1109-15.

54. Le Tourneau T, Messika-Zeitoun D, Russo A, et al. Impact of left atrial volume on clinical outcome in organic mitral regurgitation. J Am Coll Cardiol 2010;56:570-8.

55. Tribouilloy C, Grigioni F, Avierinos JF, et al. Survival implication of left ventricular end-systolic diameter in mitral regurgitation due to flail leaflets a long-term follow-up multicenter study. J Am Coll Cardiol 2009;54:1961-8.

56. Le Tourneau T, Richardson M, Juthier F, et al. Echocardiography predictors and prognostic value of pulmonary artery systolic pressure in chronic organic mitral regurgitation. Heart 2010;96:1311-17.

57. Ahmed MI, Gladden JD, Litovsky SH, et al. Increased oxidative stress and cardiomyocyte myofibrillar degeneration in patients with chronic isolated mitral regurgitation and ejection fraction >60\%. J Am Coll Cardiol 2010;55:671-9. 
58. Liang YJ, Zhang Q, Fung JW, et al. Impact of reduction in earlyand late-systolic functional mitral regurgitation on reverse remodelling after cardiac resynchronization therapy. Eur Heart J 2010;31:2359-68.

59. Bach DS, Awais M, Gurm HS, et al. Failure of guideline adherence for intervention in patients with severe mitral regurgitation. J Am Coll Cardiol 2009;54:860-5.

60. Samad Z, Kaul P, Shaw LK, et al. Impact of early surgery on survival of patients with severe mitral regurgitation. Heart 2011;97:221-4.

61. Anyanwu AC, Bridgewater B, Adams DH. The lottery of mitral valve repair surgery. Heart 2010;96:1964-7.

62. Bolling SF, Li S, O'Brien SM, et al. Predictors of mitral valve repair: clinical and surgeon factors. Ann Thorac Surg 2010;90:1904-11; discussion 1912.

63. Yosefy C, Beeri R, Guerrero JL, et al. Mitral regurgitation after anteroapical myocardial infarction: new mechanistic insights. Circulation 2011;123:1529-36.

64. Chaput M, Handschumacher MD, Guerrero JL, et al. Mitral leaflet adaptation to ventricular remodeling: prospective changes in a model of ischemic mitral regurgitation. Circulation 2009;120:S99-103.

65. de Varennes B, Chaturvedi R, Sidhu S, et al. Initial results of posterior leaflet extension for severe type IIIb ischemic mitral regurgitation. Circulation 2009;119:2837-43.

66. Dal-Bianco JP, Aikawa E, Bischoff J, et al. Active adaptation of the tethered mitral valve: insights into a compensatory mechanism for functional mitral regurgitation. Circulation 2009;120:334-42.

67. Marechaux S, Pincon C, Poueymidanette $M$, et al. Elevated left atrial pressure estimated by Doppler echocardiography is a key determinant of mitral valve tenting in functional mitral regurgitation. Heart 2010;96:289-97.

68. Lee AP, Acker M, Kubo SH, et al. Mechanisms of recurrent functional mitral regurgitation after mitral valve repair in nonischemic dilated cardiomyopathy: importance of distal anterior leaflet tethering. Circulation 2009;119:2606-14.

69. Juang JJ, Ke SR, Lin JL, et al. Rupture of mitral chordae tendineae: adding to the list of hypertension complications. Heart 2009;95:976-9.

70. Topilsky Y, Tribouilloy C, Michelena HI, et al. Pathophysiology of tricuspid regurgitation: quantitative Doppler echocardiographic assessment of respiratory dependence. Circulation 2010;122:1505-13.

71. Jaber WA, Sorajja P, Borlaug BA, et al. Differentiation of tricuspid regurgitation from constrictive pericarditis: novel criteria for diagnosis in the cardiac catheterisation laboratory. Heart 2009;95:1449-54.

72. Park K, Kim HK, Kim YJ, et al. Incremental prognostic value of early postoperative right ventricular systolic function in patients undergoing surgery for isolated severe tricuspid regurgitation. Heart 2011;97:1319-25.

73. Song $\mathrm{H}$, Kim MJ, Chung $\mathrm{CH}$, et al. Factors associated with development of late significant tricuspid regurgitation after successful left-sided valve surgery. Heart 2009;95:931-6.

74. Min SY, Song JM, Kim JH, et al. Geometric changes after tricuspid annuloplasty and predictors of residual tricuspid regurgitation: a real-time three-dimensional echocardiography study. Eur Heart J 2010;31:2871-80.

75. Topilsky Y, Khanna AD, Oh JK, et al. Preoperative factors associated with adverse outcome after tricuspid valve replacement. Circulation 2011;123:1929-39.

76. Choi JH, Cho DK, Song YB, et al. Preoperative NT-proBNP and CRP predict perioperative major cardiovascular events in non-cardiac surgery. Heart 2010;96:56-62.

77. Thuny F, Fournier PE, Casalta JP, et al. Investigation of blood culture-negative early prosthetic valve endocarditis reveals high prevalence of fungi. Heart 2010;96:743-7.

78. Chu VH, Miro JM, Hoen B, et al. Coagulase-negative staphylococcal prosthetic valve endocarditis - a contemporary update based on the International Collaboration on Endocarditis: prospective cohort study. Heart 2009;95:570-6.

79. Lopez J, Revilla A, Vilacosta I, et al. Age-dependent profile of left-sided infective endocarditis: a 3-center experience. Circulation 2010;121:892-7.
80. Lopez J, Fernandez-Hidalgo N, Revilla A, et al. Internal and external validation of a model to predict adverse outcomes in patients with left-sided infective endocarditis. Heart 2011;97:1138-42.

81. Tribouilloy C, Rusinaru D, Sorel C, et al. Clinical characteristics and outcome of infective endocarditis in adults with bicuspid aortic valves: a multicentre observational study. Heart 2010;96:1723-9.

82. Hekimian G, Kim M, Passefort S, et al. Preoperative use and safety of coronary angiography for acute aortic valve infective endocarditis. Heart 2010;96:696-700.

83. Lalani T, Cabell CH, Benjamin DK, et al. Analysis of the impact of early surgery on in-hospital mortality of native valve endocarditis: use of propensity score and instrumental variable methods to adjust for treatment-selection bias. Circulation 2010;121:1005-13.

84. Kim DH, Kang DH, Lee MZ, et al. Impact of early surgery on embolic events in patients with infective endocarditis. Circulation 2010;122:S17-22.

85. El-Hamamsy I, Eryigit Z, Stevens LM, et al. Long-term outcomes after autograft versus homograft aortic root replacement in adults with aortic valve disease: a randomised controlled trial. Lancet 2010;376:524-31.

86. Puranik R, Tsang VT, Broadley A, et al. Functional outcomes after the Ross (pulmonary autograft) procedure assessed with magnetic resonance imaging and cardiopulmonary exercise testing. Heart 2010;96:304-8.

87. Mokhles MM, Kortke H, Stierle U, et al. Survival comparison of the Ross procedure and mechanical valve replacement with optimal self-management anticoagulation therapy: propensitymatched cohort study. Circulation 2011;123:31-8.

88. Stulak JM, Burkhart HM, Sundt TM 3rd, et al. Spectrum and outcome of reoperations after the Ross procedure. Circulation 2010;122:1153-8.

89. de Arenaza DP, Pepper J, Lees B, et al. Preoperative 6-minute walk test adds prognostic information to Euroscore in patients undergoing aortic valve replacement. Heart 2010;96:113-17.

90. Rimington $\mathrm{H}$, Weinman J, Chambers JB. Predicting outcome after valve replacement. Heart 2010;96:118-23.

91. Fuchs C, Mascherbauer J, Rosenhek R, et al. Gender differences in clinical presentation and surgical outcome of aortic stenosis. Heart 2010;96:539-45.

92. Sharma A, Gilbertson DT, Herzog CA. Survival of kidney transplantation patients in the United States after cardiac valve replacement. Circulation 2010;121:2733-9.

93. Stassano P, Di Tommaso L, Monaco M, et al. Aortic valve replacement: a prospective randomized evaluation of mechanical versus biological valves in patients ages 55 to 70 years. J Am Coll Cardiol 2009;54:1862-8.

94. Stoica S, Goldsmith K, Demiris N, et al. Microsimulation and clinical outcomes analysis support a lower age threshold for use of biological valves. Heart 2010;96:1730-6.

95. Ashikhmina EA, Schaff HV, Dearani JA, et al. Aortic valve replacement in the elderly: determinants of late outcome. Circulation 2011;124:1070-8.

96. Likosky DS, Sorensen MJ, Dacey LJ, et al. Long-term survival of the very elderly undergoing aortic valve surgery. Circulation 2009;120:S127-133.

97. Bleiziffer S, Ali A, Hettich IM, et al. Impact of the indexed effective orifice area on mid-term cardiac-related mortality after aortic valve replacement. Heart 2010;96:865-71.

98. Mohty D, Dumesnil JG, Echahidi N, et al. Impact of prosthesispatient mismatch on long-term survival after aortic valve replacement: influence of age, obesity, and left ventricular dysfunction. J Am Coll Cardiol 2009;53:39-47.

99. Unger P, Magne J, Vanden Eynden F, et al. Impact of prosthesispatient mismatch on mitral regurgitation after aortic valve replacement. Heart 2010;96:1627-32.

100. Flameng W, Herregods MC, Vercalsteren M, et al. Prosthesispatient mismatch predicts structural valve degeneration in bioprosthetic heart valves. Circulation 2010;121:2123-9.

101. Shi WY, Yap CH, Hayward PA, et al. Impact of prosthesis-patient mismatch after mitral valve replacement: a multicentre analysis of early outcomes and mid-term survival. Heart 2011;97:1074-81.

102. Chikwe J, Goldstone AB, Passage J, et al. A propensity scoreadjusted retrospective comparison of early and mid-term re- 
sults of mitral valve repair versus replacement in octogenarians. Eur Heart J 2011;32:618-26.

103. Kim JB, Ju MH, Yun SC, et al. Mitral valve replacement with or without a concomitant Maze procedure in patients with atrial fibrillation. Heart 2010;96:1126-31.

104. Magne J, Girerd N, Senechal M, et al. Mitral repair versus replacement for ischemic mitral regurgitation: comparison of short-term and long-term survival. Circulation 2009;120:S104-11.

105. Penicka $\mathrm{M}$, Linkova $\mathrm{H}$, Lang $\mathrm{O}$, et al. Predictors of improvement of unrepaired moderate ischemic mitral regurgitation in patients undergoing elective isolated coronary artery bypass graft surgery. Circulation 2009;120:1474-81.

106. Bernal JM, Ponton A, Diaz B, et al. Combined mitral and tricuspid valve repair in rheumatic valve disease: fewer reoperations with prosthetic ring annuloplasty. Circulation 2010;121:1934-40.

107. Allou N, Piednoir P, Berroeta C, et al. Incidence and risk factors of early thromboembolic events after mechanical heart valve replacement in patients treated with intravenous unfractionated heparin. Heart 2009;95:1694-700.

108. Karthikeyan G, Math RS, Mathew N, et al. Accelerated infusion of streptokinase for the treatment of left-sided prosthetic valve thrombosis: a randomized controlled trial. Circulation 2009;120:1108-14.

109. Osswald BR, Gegouskov V, Badowski-Zyla D, et al. Overestimation of aortic valve replacement risk by EuroSCORE: implications for percutaneous valve replacement. Eur Heart J 2009;30:74-80.

110. R Rosenhek, B lung, P Tornos, et al. ESC Working Group on Valvular Heart Disease Position Paper: assessing the risk of interventions in patients with valvular heart disease. Eur Heart J. Published Online First: 15 March 2011.

111. Delgado V, Ng AC, van de Veire NR, et al. Transcatheter aortic valve implantation: role of multi-detector row computed tomography to evaluate prosthesis positioning and deployment in relation to valve function. Eur Heart J 2010;31:1114-23.

112. Altiok E, Koos R, Schroder J, et al. Comparison of two-dimensional and three-dimensional imaging techniques for measurement of aortic annulus diameters before transcatheter aortic valve implantation. Heart 2011;97:1578-84.

113. Messika-Zeitoun D, Serfaty JM, Brochet E, et al. Multimodal assessment of the aortic annulus diameter: implications for transcatheter aortic valve implantation. J Am Coll Cardiol 2010;55:186-94.

114. Ng AC, Yiu KH, Ewe SH, et al. Influence of left ventricular geometry and function on aortic annular dimensions as assessed with multi-detector row computed tomography: implications for transcatheter aortic valve implantation. Eur Heart J 2011;32:2806-13.

115. Schultz CJ, Weustink A, Piazza N, et al. Geometry and degree of apposition of the CoreValve ReValving system with multislice computed tomography after implantation in patients with aortic stenosis. J Am Coll Cardiol 2009;54:911-18.

116. Leon MB, Piazza N, Nikolsky E, et al. Standardized endpoint definitions for transcatheter aortic valve implantation clinical trials: a consensus report from the Valve Academic Research Consortium. Eur Heart J 2011;32:205-17.

117. Piazza N, Otten A, Schultz C, et al. Adherence to patient selection criteria in patients undergoing transcatheter aortic valve implantation with the 18F CoreValve ReValving System. Heart 2010;96:19-26.

118. Himbert D, Descoutures F, Al-Attar N, et al. Results of transfemoral or transapical aortic valve implantation following a uniform assessment in high-risk patients with aortic stenosis. J Am Coll Cardiol 2009;54:303-11.

119. Grant SW, Devbhandari MP, Grayson AD, et al. What is the impact of providing a transcatheter aortic valve implantation service on conventional aortic valve surgical activity: patient risk factors and outcomes in the first 2 years. Heart 2010;96:1633-7.

120. Webb JG, Altwegg L, Boone RH, et al. Transcatheter aortic valve implantation: impact on clinical and valve-related outcomes. Circulation 2009;119:3009-16.

121. Walther T, Schuler G, Borger MA, et al. Transapical aortic valve implantation in 100 consecutive patients: comparison to pro- pensity-matched conventional aortic valve replacement. Eur Heart J 2010;31:1398-403.

122. Gurvitch R, Wood DA, Tay EL, et al. Transcatheter aortic valve implantation: durability of clinical and hemodynamic outcomes beyond 3 years in a large patient cohort. Circulation 2010;122:1319-27.

123. Leon MB, Smith CR, Mack M, et al. Transcatheter aortic-valve implantation for aortic stenosis in patients who cannot undergo surgery. N Engl J Med 2010;363:1597-607.

124. Smith CR, Leon MB, Mack MJ, et al. Transcatheter versus surgical aortic-valve replacement in high-risk patients. N Engl J Med 2011;364:2187-98.

125. Thomas M, Schymik G, Walther T, et al. One-year outcomes of cohort 1 in the Edwards SAPIEN Aortic Bioprosthesis European Outcome (SOURCE) registry: the European registry of transcatheter aortic valve implantation using the Edwards SAPIEN valve. Circulation 2011;124:425-33.

126. Lefevre T, Kappetein AP, Wolner E, et al. One year follow-up of the multi-centre European PARTNER transcatheter heart valve study. Eur Heart J 2011;32:148-57.

127. Eltchaninoff $\mathrm{H}$, Prat $\mathrm{A}$, Gilard $\mathrm{M}$, et al. Transcatheter aortic valve implantation: early results of the FRANCE (FRench Aortic National CoreValve and Edwards) registry. Eur Heart 2011;32:191-7.

128. Zahn R, Gerckens U, Grube E, et al. Transcatheter aortic valve implantation: first results from a multi-centre real-world registry. Eur Heart J 2011;32:198-204.

129. Tamburino C, Capodanno D, Ramondo A, et al. Incidence and predictors of early and late mortality after transcatheter aortic valve implantation in 663 patients with severe aortic stenosis. Circulation 2011;123:299-308.

130. Rodes-Cabau J, Webb JG, Cheung A, et al. Transcatheter aortic valve implantation for the treatment of severe symptomatic aortic stenosis in patients at very high or prohibitive surgical risk: acute and late outcomes of the multicenter Canadian experience. J Am Coll Cardiol 2010;55:1080-90.

131. Buellesfeld L, Gerckens U, Schuler G, et al. 2-year follow-up of patients undergoing transcatheter aortic valve implantation using a self-expanding valve prosthesis. J Am Coll Cardiol 2011;57:1650-7.

132. Clavel MA, Webb JG, Pibarot $P$, et al. Comparison of the hemodynamic performance of percutaneous and surgical bioprostheses for the treatment of severe aortic stenosis. J Am Coll Cardiol 2009;53:1883-91.

133. Kalavrouziotis D, Rodes-Cabau J, Bagur R, et al. Transcatheter aortic valve implantation in patients with severe aortic stenosis and small aortic annulus. J Am Coll Cardiol 2011;58:1016-24.

134. Clavel MA, Webb JG, Rodes-Cabau J, et al. Comparison between transcatheter and surgical prosthetic valve implantation in patients with severe aortic stenosis and reduced left ventricular ejection fraction. Circulation 2010;122:1928-36.

135. Buellesfeld L, Wenaweser P, Gerckens U, et al. Transcatheter aortic valve implantation: predictors of procedural successthe Siegburg-Bern experience. Eur Heart J 2010;31:984-91.

136. Gotzmann M, Hehen T, Germing A, et al. Short-term effects of transcatheter aortic valve implantation on neurohormonal activation, quality of life and 6-minute walk test in severe and symptomatic aortic stenosis. Heart 2010;96:1102-6.

137. Bagur R, Webb JG, Nietlispach F, et al. Acute kidney injury following transcatheter aortic valve implantation: predictive factors, prognostic value, and comparison with surgical aortic valve replacement. Eur Heart J 2010;31:865-74.

138. Rodes-Cabau J, Gutierrez M, Bagur R, et al. Incidence, predictive factors, and prognostic value of myocardial injury following uncomplicated transcatheter aortic valve implantation. J Am Coll Cardiol 2011;57:1988-99.

139. Abdel-Wahab M, Zahn R, Horack M, et al. Aortic regurgitation after transcatheter aortic valve implantation: incidence and early outcome. Results from the German transcatheter aortic valve interventions registry. Heart 2011;97:899-906.

140. Sherif MA, Abdel-Wahab M, Stocker B, et al. Anatomic and procedural predictors of paravalvular aortic regurgitation after implantation of the Medtronic CoreValve bioprosthesis. J Am Coll Cardiol 2010;56:1623-9. 
141. Ghanem A, Muller A, Nahle CP, et al. Risk and fate of cerebra embolism after transfemoral aortic valve implantation: a prospective pilot study with diffusion-weighted magnetic resonance imaging. J Am Coll Cardiol 2010;55:1427-32.

142. Kahlert P, Knipp SC, Schlamann M, et al. Silent and apparent cerebral ischemia after percutaneous transfemoral aortic valve implantation: a diffusion-weighted magnetic resonance imaging study. Circulation 2010;121:870-8.

143. Rodes-Cabau J, Dumont E, Boone RH, et al. Cerebral embolism following transcatheter aortic valve implantation: comparison of transfemoral and transapical approaches. J Am Coll Cardiol 2011;57:18-28.

144. Ussia GP, Barbanti M, Ramondo A, et al. The valve-in-valve technique for treatment of aortic bioprosthesis malposition an analysis of incidence and 1-year clinical outcomes from the italian CoreValve registry. J Am Coll Cardiol 2011;57:1062-8.

145. Webb JG, Wood DA, Ye J, et al. Transcatheter valve-in-valve implantation for failed bioprosthetic heart valves. Circulation 2010;121:1848-57.

146. Asoh K, Walsh M, Hickey E, et al. Percutaneous pulmonary valve implantation within bioprosthetic valves. Eur Heart $J$ 2010;31:1404-9.

147. Eicken A, Ewert P, Hager A, et al. Percutaneous pulmonary valve implantation: two-centre experience with more than 100 patients. Eur Heart J 2011;32:1260-5.

148. McElhinney DB, Hellenbrand WE, Zahn EM, et al. Short- and medium-term outcomes after transcatheter pulmonary valve placement in the expanded multicenter US melody valve trial. Circulation 2010;122:507-16.

149. Nordmeyer J, Lurz P, Khambadkone S, et al. Pre-stenting with a bare metal stent before percutaneous pulmonary valve implantation: acute and 1-year outcomes. Heart 2011;97:118-23.
150. Roberts PA, Boudjemline Y, Cheatham JP, et al. Percutaneous tricuspid valve replacement in congenital and acquired heart disease. J Am Coll Cardiol 2011;58:117-22.

151. Farouque HM, Clark DJ. Percutaneous mitral valve leaflet repair for mitral regurgitation: NICE guidance. Heart 2010;96:385-7.

152. Feldman T, Kar S, Rinaldi M, et al. Percutaneous mitral repair with the MitraClip system: safety and midterm durability in the initial EVEREST (Endovascular Valve Edge-to-Edge REpair Study) cohort. J Am Coll Cardiol 2009;54:686-94.

153. Feldman T, Foster E, Glower DD, et al. Percutaneous repair or surgery for mitral regurgitation. N Engl J Med 2011;364:1395-406.

154. Siegel RJ, Biner S, Rafique AM, et al. The acute hemodynamic effects of MitraClip therapy. J Am Coll Cardiol 2011;57:1658-65.

155. Ladich E, Michaels MB, Jones RM, et al. Pathological healing response of explanted MitraClip devices. Circulation 2011;123:1418-27.

156. Schofer J, Siminiak T, Haude M, et al. Percutaneous mitral annuloplasty for functional mitral regurgitation: results of the CARILLON Mitral Annuloplasty Device European Union Study. Circulation 2009;120:326-33.

157. Ineid H, Cruz-Gonzalez I, Sanchez-Ledesma M, et al. Impact of pre- and postprocedural mitral regurgitation on outcomes after percutaneous mitral valvuloplasty for mitral stenosis. Am J Cardiol 2009;104:1122-7.

158. Kim KH, Kim YJ, Shin DH, et al. Left atrial remodelling in patients with successful percutaneous mitral valvuloplasty: determinants and impact on long-term clinical outcome. Heart 2010;96:1050-5.

159. Song JK, Song JM, Kang DH, et al. Restenosis and adverse clinical events after successful percutaneous mitral valvuloplasty: immediate post-procedural mitral valve area as an important prognosticator. Eur Heart J 2009;30:1254-62. 